\title{
TGM3 functions as a tumor suppressor by repressing epithelial-to-mesenchymal transition and the PI3K/AKT signaling pathway in colorectal cancer
}

\author{
YIFEI FENG $^{1 *}$, DONGJIAN JI ${ }^{1,2 *}$, YUANJIAN HUANG $^{1 *}$, BING JI $^{3}$, YUE ZHANG $^{1}$, JIE LI $^{1,2}$, \\ WEN PENG ${ }^{1,2}$, CHUAN ZHANG ${ }^{1}$, DONGSHENG ZHANG ${ }^{1}$, YUEMING SUN ${ }^{1}$ and ZIWEI XU ${ }^{1}$ \\ ${ }^{1}$ Department of Colorectal Surgery, The First Affiliated Hospital of Nanjing Medical University; \\ ${ }^{2}$ The First School of Clinical Medicine, Nanjing Medical University, Nanjing, Jiangsu 210029; \\ ${ }^{3}$ Department of General Surgery, Yancheng City No. 1 People's Hospital, Yancheng, Jiangsu 224005, P.R. China
}

Received September 26, 2018; Accepted November 19, 2019

DOI: $10.3892 / o r .2020 .7474$

\begin{abstract}
The dysregulation of transcription factors contributes to the unlimited proliferation of cancer cells Transglutaminase 3 (TGM3) has been demonstrated to play a crucial role in physiology and pathology. However, the potential role of TGM3 in colorectal cancer (CRC) remains unknown. In the present study, reverse transcription-quantitative PCR and immunohistochemistry were utilized to analyze the expression of TGM3 in CRC and adjacent normal tissues. LoVo and HCT116 cell lines were then selected to further investigate the function of TGM3 in the proliferation, invasion and metastasis of CRC both in vitro and in vivo. Finally, western blotting was performed to investigate the molecular mechanisms underlying the effects of TGM3 in CRC. The expression level of TGM3 was significantly downregulated in CRC tissues, and was associated with tumor invasion, metastasis and patient prognosis. Following TGM3 inhibition and overexpression in CRC cells, it was revealed that TGM3 suppressed cell proliferation, potentially via the promotion of apoptosis and cell cycle regulation. Furthermore, TGM3 also inhibited invasion and metastasis. Finally, it was observed that TGM3 inhibited epithelial-to-mesenchymal transition and activated phosphorylated AKT serine/threonine kinase in CRC cells. The results from the present study revealed that
\end{abstract}

Correspondence to: Dr Yueming Sun or Dr Ziwei Xu, Department of Colorectal Surgery, The First Affiliated Hospital of Nanjing Medical University, 300 Guangzhou Road, Nanjing, Jiangsu 210029, P.R. China

E-mail: jssym@vip.sina.com

E-mail: xzwwin2003@163.com

${ }^{*}$ Contributed equally

Key words: TGM3, colorectal cancer, epithelial-mesenchymal transition, PI3K-AKT pathway
TGM3 is a tumor suppressor in the progression of CRC, and may be used as a novel target for CRC treatment.

\section{Introduction}

Colorectal cancer (CRC) is the third and second most commonly diagnosed cancer in males and females, respectively, worldwide (1). The 5-year survival rate of patients with CRC at the localized stage in the USA between 2008 and 2012 was $90.3 \%$, which was an $~ 8$-fold change compared with patients with distant metastasis, emphasizing the importance of early diagnosis and surgical treatment. However, only 59\% of patients with CRC are diagnosed at the localized stage (2). Therefore, investigations that aim to elucidate the molecular mechanisms underlying $\mathrm{CRC}$ are urgently required in order to improve the rate of early diagnosis.

Transglutaminase 3 (TGM3), reported as an enzyme that can catalyze the irreversible cross-linking of peptide-bound glutamine residues either with peptide-bound lysines or with primary amines, is widely expressed in a number of different types of tissue, including the small intestine, brain, skin and mucosa (3). Recently, studies have revealed that TGM3 plays a significant role in physiology and pathology. In the skin and mucosa, TGM3 is essential for epidermal terminal differentiation and the formation of the cornified cell envelope through cross-linking structural proteins such as involucrin, loricrin and small proline-rich proteins (4). Furthermore, the downregulation of TGM3 is associated with a variety of different types of human cancer, such as esophageal carcinoma, laryngeal carcinoma and oral squamous cell carcinoma (OSCC). In addition, TGM3 expression is different in node-positive and node-negative primary tumors in patients with OSCC, which implies that the decreased expression of TGM3 may cause the metastatic potential of OSCC. It is worth noting that TGM3 is a candidate tumor suppressor in the carcinogenesis and development of head and neck cancer (HNC) (5-7). However, whether there is an association between TGM3 and colorectal carcinoma remain unclear. In addition, the biological function and molecular mechanism of TGM3 in colorectal carcinoma have also not yet been reported. 
Epithelial-to-mesenchymal transition (EMT), a developmental process of cell alteration from an epithelial state toward a mesenchymal state, modifies the adhesion molecules expressed by the cell, allowing it to adopt a migratory and invasive behavior (8). A variety of studies have demonstrated that EMT plays a critical role in the initiation of cancer cell metastasis (9). This process involves the loss of the expression of epithelial cell adhesion molecules such as E-cadherin, accompanied by the acquisition of mesenchymal molecules, such as vimentin and N-cadherin. Multiple regulatory mechanisms are involved in the regulation of EMT, among which activation of phosphatidylinositol 3-kinase (PI3K)/protein kinase B (AKT) have been extensively studied (10). However, the association between TGM3 and EMT in CRC has not yet been widely investigated.

The present study aimed to analyze the expression of TGM3 in CRC and paired adjacent normal tissues. Gain- and loss-of-function assays were performed in order to further investigate the biological role of TGM3 in CRC cells both in vivo and in vitro via knockdown and overexpression of TGM3. Finally, the potential molecular mechanisms underlying the effects of TGM3 in the progression of CRC were investigated.

\section{Materials and methods}

Patients and tissue samples. All tissues were supplied from the tissue bank of the First Affiliated Hospital of Nanjing Medical University (ethical approval no. 2010-SR-091.A1). In total, 100 pairs of tissue samples were used in the present study, obtained from patients with CRC between January, 2011 and December, 2013, including CRC tissues and adjacent noncancerous tissues. The average age of the patients (male: 68, female: 32) was 58.7 years (range, 24-81 years), and no patients had received radiotherapy or chemotherapy prior to surgery. All specimens were stored in liquid nitrogen within $5 \mathrm{~min}$ of excision, and then stored for long-term conservation at $-70^{\circ} \mathrm{C}$. The Tumor-Node-Metastasis (TNM) stage was assigned to each sample according to the National Comprehensive Cancer Network (https://www.nccn.org/). Informed consent was obtained from human participants or their family members.

Cell culture. All cell lines (HCT116, SW480, LoVo, DLD-1, NCM460) were supplied by the American Type Culture Collection (ATCC). All cell lines used in this study were authenticated with STR profiling. Cells were cultured in DMEM mixed with $10 \%$ fetal bovine serum (Winsent, Inc.), and penicillin (100 $\mu \mathrm{g} / \mathrm{ml})$ (Invitrogen; Thermo Fisher Scientific, Inc.) at $37^{\circ} \mathrm{C}$ in a humidified incubator with $5 \% \mathrm{CO}_{2}$. MK-2206 2HCl (Selleck) was dissolved in DMSO at a stock concentration of $10 \mathrm{mM}$ and added to cell cultures at a final concentration of $10 \mu \mathrm{M}$. We found that the final concentration of DMSO used in our study did not affect cell survival or protein phosphorylation.

$R N A$ isolation and reverse transcription-quantitative $P C R$ $(R T-q P C R)$. RNAs were extracted from tissues and CRC cell lines using TRIzol ${ }^{\circledR}$ reagent (Invitrogen; Thermo Fisher Scientific, Inc.) according to the manufacturer's protocol. PrimeScript RT Master Mix was used to reverse transcribe the isolated RNAs (Takara Bio Inc.).
A SYBR-Green PCR kit (Roche Diagnostics) was used alongside SYBR $(10 \mu \mathrm{l})$, cDNA $(2 \mu \mathrm{l})$, primers $(1.2 \mu \mathrm{l})$ and $\mathrm{dH}_{2} \mathrm{O}(6.8 \mu \mathrm{l})$ as the buffer of the RT-qPCR system. The StepOnePlus Real-time PCR system (Applied Biosystems; Thermo Fisher Scientific, Inc) was used for the final reaction. The thermocycling conditions were as follows: Hot-start DNA polymerase activation $\left(95^{\circ} \mathrm{C} ; 10 \mathrm{~min}\right) ; 40$ cycles $\left(95^{\circ} \mathrm{C} ; 15 \mathrm{sec}\right.$ and $\left.60^{\circ} \mathrm{C} ; 1 \mathrm{~min}\right)$; and last melt curve analysis $\left(95^{\circ} \mathrm{C} ; 15 \mathrm{sec}\right.$, $60^{\circ} \mathrm{C} ; 1 \mathrm{~min}$ and $95^{\circ} \mathrm{C} ; 15 \mathrm{sec}$ ).

The primer sequences used were: GAPDH forward, 5'-GGAGCGAGATCCCTCCAAAAT-3' and reverse, 5'-GGC TGTTGTCATACTTCTCATGG-3'; TGM3 forward, 5'-ATG GCTGCTCTAGGAGTCCAG-3' and reverse, 5'-GTTTTG GCCTCTCCGCAAGAT-3'.

Immunohistochemistry (IHC). All tissues were fixed in $4 \%$ paraformaldehyde overnight at $4^{\circ} \mathrm{C}$, processed, and sectioned into slices $4-\mu \mathrm{m}$ thick. Xylene was used for dewaxing the tissue sections and different concentrations of alcohol and distilled water were used for rehydrating, followed by microwave antigen retrieval. Sections were deparaffinized followed by rehydration steps through a graded ethanol series and distilled water and treated with $3 \% \mathrm{H}_{2} \mathrm{O}_{2}$ in methanol for 30 min to block endogenous peroxidase activity. Sections were then washed with PBS three times and immersed in $5 \%$ bovine serum albumin (Servicebio) for $1 \mathrm{~h}$. The slides were incubated with primary antibody (dilution 1:1,000) overnight at $4^{\circ} \mathrm{C}$. Negative controls were prepared by replacing the primary antibody with either serum or antibody dilution buffer. The slides were incubated the next day with secondary anti-rabbit antibodies (dilution 1:1,000) at room temperature for $1 \mathrm{~h}$, alongside the color agent diaminobenzidine. The nuclei were counterstained with hematoxylin, and different grades of ethyl alcohol and xylene were using to dehydrate the sections. After staining, an inverted microscope was used to observe sections (Nikon Eclipse TI-SR; Nikon Corporation). The grade of TGM3 included 0 (no staining), $1(+), 2(++)$ and $3(+++)$, according to the staining intensity. The scores represented the following values of staining intensity: 0 , negative; $1,<30 ; 2,31-60$; and $3,>60 \%$, according to the proportion of TGM3-positive cells. The total score was equal to the intensity score plus the positive rate score. Scores $\geq 4$ were considered as TGM3-high level, and scores $<4$ were considered as TGM3-low level. The antibodies used were as follows: Polyclonal rabbit anti-TGM3 primary antibody was used (cat. no. ab78393; Abcam) and polyclonal anti-rabbit horseradish peroxidase conjugated secondary antibody was used (dilution 1:1,000; cat. no. ab6721; Abcam).

Knockdown and overexpression of TGM3. Short hairpin (sh)RNAs of TGM3 were designed for the target sequence: Sh1, GCATCTGCCTCTCAATCTTGG; sh2, GCACAAACCGAA TTGGCATGA. The synthesized and purified TGM3 gene fragment was inserted into a lentivirus vector (PCDH), termed LV-TGM3. Recombinant lentivirus was generated from 293T cells using Lipofectamine ${ }^{\circledR} 3000$ (Invitrogen; Thermo Fisher Scientific, Inc.), and transfected into CRC cell lines mediated by polybrene ( $8 \mu \mathrm{g} / \mathrm{ml}$, Sigma-Aldrich; Merck KGaA).

Cell viability assay. In order to detect the function of TGM3 in the proliferation of CRC cells, cells $\left(3 \times 10^{3}\right.$ cells/well) were 

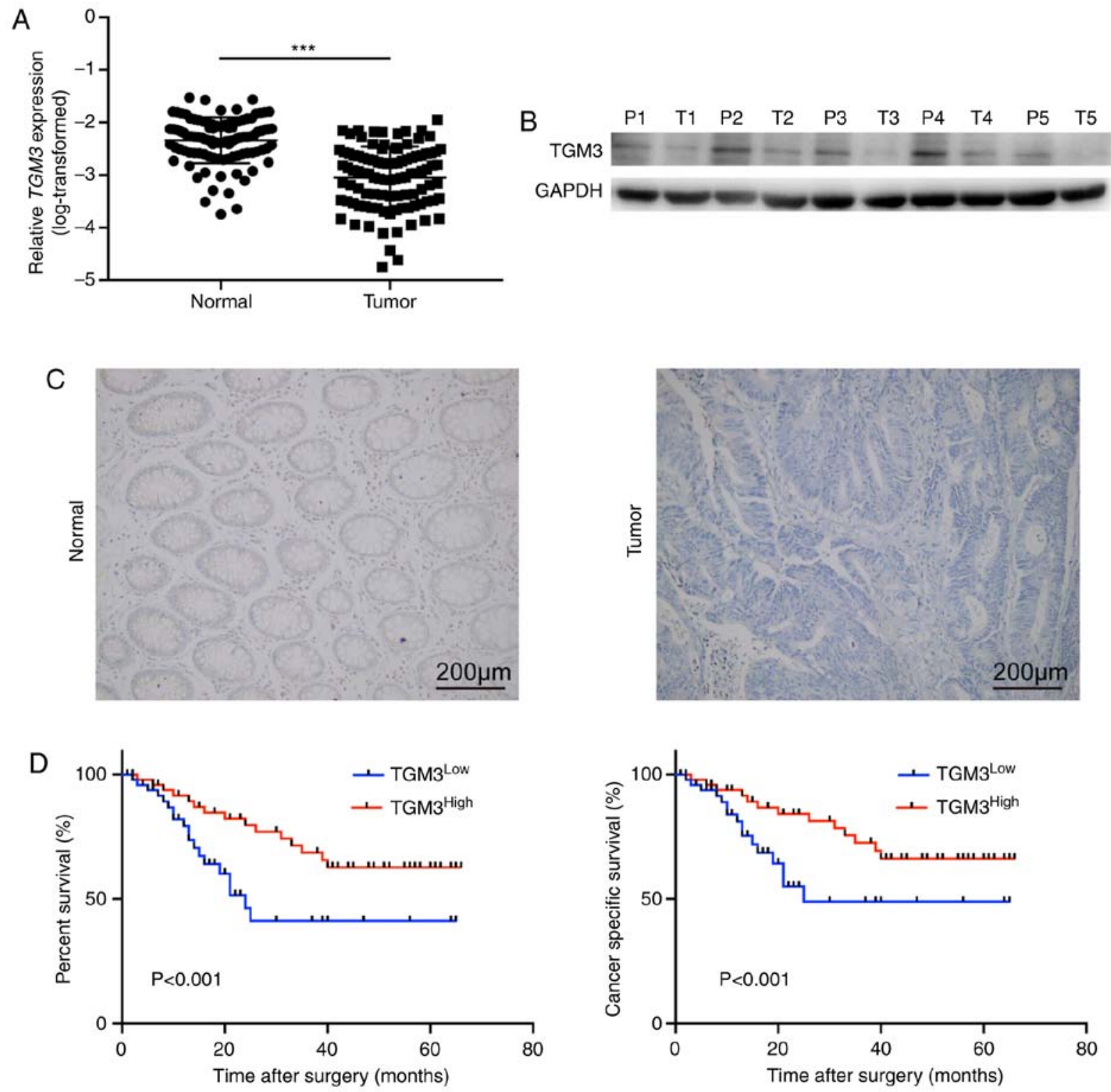

Figure 1. TGM3 is downregulated in human CRC tissues and predicts improved prognosis. (A) TGM3 expression at the mRNA level in CRC and normal tissues $(\mathrm{n}=100)$ was detected by RT-qPCR. mRNA expression of TGM3 was normalized to GAPDH. ${ }^{* * *} \mathrm{P}<0.001$ (B) Immunoblot analysis of TGM3 protein in both human CRC (T1-5) and normal tissue (P1-5) samples. Target protein bands were quantified relative to GAPDH. (C) Representative images of TGM3 staining. (D) The log-rank test was used to calculate the overall survival and recurrence-free survival of patients with high and low TGM3 expression.

cultured in 96-well plates with $100 \mu 1$ of medium/well. To detect the cell viability, a Cell Counting Kit-8 (CCK-8) was used (Dojindo Molecular Technologies, Inc.). Briefly, CCK-8 assay reagent $(10 \mu \mathrm{l})$ mixed with serum-free medium $(90 \mu \mathrm{l})$ was added into each well. The viability was measured every $24 \mathrm{~h}$ from 0 to $96 \mathrm{~h}$, and the absorbance was detected $2 \mathrm{~h}$ later using a microplate reader $(450 \mathrm{~nm}$ as the test wavelength and $630 \mathrm{~nm}$ as the reference wavelength).

Cell migration and invasion assay. Cell migration and invasion were determined using Transwell chambers $(8-\mu \mathrm{m}$ pore size; EMD Millipore). In the migration assay, cells were cultured in the upper chamber with serum-free medium. In the invasion assay, medium supplemented with $10 \%$ FBS was added to the lower chamber. After $48 \mathrm{~h}$, cells that had migrated or invaded through the membrane were fixed with
4\% methanol, stained with crystal violet (Beyotime) for $15 \mathrm{~min}$. The chamber was then washed with PBS three times, and a cotton bud was used to remove cells and medium from the upper chambers. The migrated and invaded cells in the lower chambers were observed under a light microscope (NIKON ECLIPSE TI-SR; Nikon Corporation; magnification, $\mathrm{x} 200$ ). The cell number was calculated as the mean value of three visions for each chamber. Triplicate chambers were counted for each sample.

Cell apoptosis and cell cycle analysis. Cells were transfected with siRNA or plasmids for $48 \mathrm{~h}$ and then collected for analysis.

For the cell apoptosis analysis, all cells were obtained in flow cytometry tubes and Annexin V-FITC Apoptosis Detection kit I (BD Biosciences) was used to stain the cells. 
Table I. Correlation between TGM3 expression and clinicopathological characteristics of the CRC patients $(\mathrm{n}=100)$.

\begin{tabular}{|c|c|c|c|c|c|c|}
\hline \multirow[b]{3}{*}{ Clinicopathological features } & \multirow{3}{*}{$\begin{array}{c}\cdot \\
\text { Total no. } \\
(\mathrm{n}=100)\end{array}$} & \multicolumn{4}{|c|}{ TGM3 expression } & \multirow[b]{3}{*}{ P-value } \\
\hline & & \multicolumn{2}{|c|}{ Low } & \multicolumn{2}{|c|}{ High } & \\
\hline & & $\mathrm{n}$ & $\%$ & $\mathrm{n}$ & $\%$ & \\
\hline Sex & & & & & & 0.668 \\
\hline Male & 68 & 33 & 66.0 & 35 & 70.0 & \\
\hline Female & 32 & 17 & 34.0 & 15 & 30.0 & \\
\hline Age (years) & & & & & & 0.406 \\
\hline$\leq 50$ & 64 & 30 & 60.0 & 34 & 68.0 & \\
\hline$>50$ & 36 & 20 & 40.0 & 16 & 32.0 & \\
\hline Depth of invasion & & & & & & 0.026 \\
\hline $\mathrm{T} 1-\mathrm{T} 2$ & 57 & 23 & 44.0 & 34 & 68.0 & \\
\hline $\mathrm{T} 3-\mathrm{T} 4$ & 33 & 27 & 56.0 & 16 & 32.0 & \\
\hline Tumor stage & & & & & & 0.001 \\
\hline I-II & 43 & 13 & 26.0 & 30 & 60.0 & \\
\hline III-IV & 57 & 37 & 74.0 & 20 & 40.0 & \\
\hline Liver metastasis & & & & & & 0.016 \\
\hline Yes & 50 & 30 & 60.0 & 26 & 52.0 & \\
\hline No & 50 & 20 & 40.0 & 24 & 48.0 & \\
\hline Lymph node metastasis & & & & & & 0.420 \\
\hline Yes & 44 & 20 & 40.0 & 24 & 48.0 & \\
\hline No & 56 & 30 & 60.0 & 26 & 52.0 & \\
\hline Location & & & & & & 0.543 \\
\hline Rectum & 63 & 33 & 66.0 & 30 & 60.0 & \\
\hline Colon & 37 & 17 & 34.0 & 20 & 40.0 & \\
\hline CEA (ng/ml) & & & & & & 0.838 \\
\hline$\geq 4.7$ & 61 & 31 & 62.0 & 30 & 60.0 & \\
\hline$<4.7$ & 39 & 19 & 38.0 & 20 & 40.0 & \\
\hline
\end{tabular}

Data were analyzed by the Chi-squared test. P-values in bold indicate statistically significant results. CRC, colorectal cancer; TGM3, transglutaminase 3; CEA, carcinoembryonic antigen; $n$, number of patients.

For the cell cycle analysis, cells were washed in PBS, and then $75 \%$ ethyl alcohol was used to mix the cells overnight at $4^{\circ} \mathrm{C}$. The next day, all cells were extracted from the separated ethyl alcohol and stained with propidium iodide (PI) staining solution $(500 \mu \mathrm{l})$ for $30 \mathrm{~min}$ in the dark at room temperature.

Following staining of the cells, flow cytometry (BD Biosciences) was used to detect the number of apoptotic cells. A FACSCalibur flow cytometer alongside CellQuest software (version 3.0; BD Biosciences) and fluorescence-activated cell sorting was used to analyze the cell cycle.

Plate colony formation assay. In order to elucidate the function that TGM3 has on the influence of colony formation in CRC cells, cells were cultured in 6-well plates at a density of 500 cells/well. The cells from each well were collected and washed with PBS three times after 7 days. The cells were then fixed in $4 \%$ ethyl alcohol for $30 \mathrm{sec}$, and crystal violet dye was used to stain for $20 \mathrm{~min}$. Finally, each well was washed again.
Colonies were defined as $\geq 50$ cells, and images were captured using a digital camera (Canon DS126211; Canon) in order to count and image the colonies.

Western blot analysis. Proteins were extracted from tissues or cultured cells using RIPA buffer containing phenylmethanesulfonyl fluoride (Beyotime Institute of Biotechnology). The protein concentration was then measured using a Bicinchoninic Acid Protein Assay kit (Beyotime Institute of Biotechnology), which determined the quantity loaded for the subsequent SDS-PAGE. Equal amounts of proteins $(40 \mu \mathrm{g})$ were separated via SDS-PAGE (15\%) and transferred to polyvinylidene fluoride membranes. The membranes were incubated with $5 \%$ bovine serum albumin for $>2 \mathrm{~h}$ and incubated with specific primary antibodies at $4^{\circ} \mathrm{C}$ overnight.

The next day, the membranes were washed with TBST three times (10 min each) and incubated with secondary antibodies (anti-rabbit or anti-mouse) at room temperature for $2 \mathrm{~h}$. Equal amounts of protein loading in each lane were confirmed 
Table II. Univariate and multivariate survival analyses for the evaluation of TGM3 expression influencing OS in CRC ( $\mathrm{n}=100$ ).

\begin{tabular}{|c|c|c|c|c|}
\hline \multirow[b]{2}{*}{ Variable } & \multicolumn{2}{|c|}{ Univariate analysis } & \multicolumn{2}{|c|}{ Multivariate analysis } \\
\hline & $\mathrm{HR}(95 \% \mathrm{CI})$ & P-value & $\operatorname{HR}(95 \% \mathrm{CI})$ & P-value \\
\hline Sex & & 0.627 & & NA \\
\hline Male & 1 & & & \\
\hline Female & $0.670(0.301-1.358)$ & & & \\
\hline Age (years) & & 0.589 & & NA \\
\hline$\leq 50$ & 1 & & & \\
\hline$>50$ & $0.853(0.595-1.436)$ & & & \\
\hline Depth of invasion & & 0.018 & & 0.133 \\
\hline $\mathrm{T} 1-\mathrm{T} 2$ & 1 & & 1 & \\
\hline T3-T4 & $1.501(1.120-2.750)$ & & $1.559(0.895-2.154)$ & \\
\hline Tumor stage & & 0.010 & & 0.013 \\
\hline I-II & 1 & & 1 & \\
\hline III-IV & $2.176(1.207-3.923)$ & & $2.201(1.178-4.113)$ & \\
\hline Liver metastasis & & 0.031 & & 0.017 \\
\hline No & 1 & & 1 & \\
\hline Yes & $1.761(1.057-3.366)$ & & $1.546(1.319-1.883)$ & \\
\hline Lymph node metastasis & & 0.008 & & 0.003 \\
\hline No & 1 & & 1 & \\
\hline Yes & $2.252(1.225-4.139)$ & & $2.601(1.379-4.907)$ & \\
\hline Location & & 0.372 & & NA \\
\hline Rectum & 1 & & & \\
\hline Colon & $1.306(0.726-2.350)$ & & & \\
\hline CEA (ng/ml) & & 0.661 & & NA \\
\hline$\geq 4.7$ & 1 & & & \\
\hline$<4.7$ & $0.760(0.595-1.366)$ & & & \\
\hline TGM3 expression & & 0.019 & & 0.031 \\
\hline Low & 1 & & 1 & \\
\hline High & $0.436(0.153-0.826)$ & & $0.480(0.183-0.891)$ & \\
\hline
\end{tabular}

All the results were adjusted using Cox proportional hazards models for depth of invasion, tumor stage, liver metastasis, lymph node metastasis and TGM3 expression. P-values in bold indicate statistically significant results. OS, overall survival; CRC, colorectal cancer; HR, hazard ratio; CI, confidence interval; NA, not applicable; CEA, carcinoembryonic antigen; TGM3, transglutaminase 3.

using GAPDH antibody. ImageJ software 1.47 (National Institutes of Health, Bethesda, MD, USA) was used to quantify the integrated density of the bands.

The primary and secondary antibodies used were as follows: Anti-TGM3 (dilution 1:1,000; cat. no. Ab27001); anti-N-cadherin (dilution 1:1,000; cat. no. Ab18203); anti-E-cadherin (dilution 1:500; cat. no. Ab1416); anti-AKT (dilution 1:500; cat. no. Ab8805); anti-p-AKT (dilution 1:500; cat. no. Ab38449); anti-P21 (dilution 1:500; cat. no. Ab38449); anti-vimentin (dilution 1:2,000; cat. no. Ab92547); anti-rabbit or anti-mouse (dilution 1:5,000; cat. no. GAB007) (all from Hangzhou Multi Sciences Biotech Co., Ltd.). Anti-GAPDH (dilution 1:5,000; Abcam) was used as the loading control throughout.

Subcutaneous xenotransplantation model and lung metastasis model. All animal experiments were approved by the Animal Ethics Committee of Nanjing Medical University. Mice were maintained in 12-h light/dark cycles (lights on at 6:00 a.m.). In order to detect the function of TGM3 on tumor growth in mice, 20 4-week-old male mice (weight, 13-15 g) were used in the present study. For subcutaneous xenotransplantation model, the nude mice $(n=10)$ were anesthetized with isoflurane and injected with shNC and shTGM3-1 HCT-116 cells $\left(2 \times 10^{6}\right)$ suspended in PBS $(200 \mu l)$. After 4 weeks, and mice were sacrificed by carbon dioxide inhalation (air displacement rate: 20\%/min; Yuyan Instruments Co., Shanghai, China) and the tumor tissues were surgically removed. For lung metastasis model, the nude mice $(n=10)$ were anesthetized with isoflurane and injected with LV-NC and LV-TGM3 LoVo cells $\left(2 \times 10^{6}\right)$ suspended in PBS $(200 \mu 1)$ After 5 weeks, and mice were sacrificed by carbon dioxide inhalation (air displacement rate: $20 \% / \mathrm{min}$; Yuyan Instruments Co.) and the lung tissues were surgically removed. 
Table III. Univariate and multivariate survival analyses for evaluation of TGM3 expression influencing DFS in CRC ( $\mathrm{n=100).}$

\begin{tabular}{|c|c|c|c|c|}
\hline \multirow[b]{2}{*}{ Variable } & \multicolumn{2}{|c|}{ Univariate } & \multicolumn{2}{|c|}{ Multivariate analysis } \\
\hline & HR $(95 \% \mathrm{CI})$ & $\mathrm{P}$-value & $\mathrm{HR}(95 \% \mathrm{CI})$ & P-value \\
\hline Sex & & 0.710 & & NA \\
\hline Male & 1 & & & \\
\hline Female & $0.921(0.538-1.712)$ & & & \\
\hline Age (years) & & 0.461 & & NA \\
\hline$\leq 50$ & 1 & & & \\
\hline$>50$ & $0.710(0.352-1.413)$ & & & \\
\hline Depth of invasion & & 0.136 & & NA \\
\hline $\mathrm{T} 1-\mathrm{T} 2$ & 1 & & & \\
\hline $\mathrm{T} 3-\mathrm{T} 4$ & $1.245(0.822-2.493)$ & & & \\
\hline Tumor stage & & 0.006 & & 0.024 \\
\hline I-II & 1 & & 1 & \\
\hline III-IV & $2.625(1.310-4.292)$ & & $2.257(1.114-4.573)$ & \\
\hline Liver metastasis & & 0.011 & & 0.022 \\
\hline No & 1 & & 1 & \\
\hline Yes & $1.641(1.138-3.288)$ & & $1.701(1.154-2.988)$ & \\
\hline Lymph node metastasis & & 0.009 & & 0.011 \\
\hline No & 1 & & 1 & \\
\hline Yes & $1.663(1.223-3.326)$ & & $1.687(1.235-3.098)$ & \\
\hline Location & & 0.350 & & NA \\
\hline Rectum & 1 & & & \\
\hline Colon & $1.447(0.832-2.326)$ & & & \\
\hline $\mathrm{CEA}(\mathrm{ng} / \mathrm{ml})$ & & 0.591 & & NA \\
\hline$\geq 4.7$ & 1 & & & \\
\hline$<4.7$ & $0.819(0.695-1.591)$ & & & \\
\hline TGM3 expression & & 0.010 & & 0.022 \\
\hline Low & 1 & & 1 & \\
\hline High & $0.434(0.211-0.881)$ & & $0.480(0.253-0.891)$ & \\
\hline
\end{tabular}

All the results were adjusted using Cox proportional hazards models for tumor stage, liver metastasis, lymph node metastasis and TGM3 expression. P-values in bold indicate statistically significant results. CRC, colorectal cancer; DFS, disease-free survival; HR, hazard ratio; CI, confidence interval; NA, not applicable; CEA, carcinoembryonic antigen; TGM3, transglutaminase 3.

Statistical analysis. Data of the in vitro experiments are presented as the mean \pm standard error of the mean from three independent experiments $(\mathrm{n}=3)$, and data of the in vivo experiments are presented as the mean \pm standard deviation $(n=10) . P<0.05$ was considered to indicate a statistically significant result. Unpaired t-tests were used to analyze the mRNA expression, while $\chi^{2}$ tests were used to analyze IHC and the clinical features. The datasets including multiple groups were compared by one-way analysis of variance and the post hoc Tukey's test. The Kaplan-Meier method was used to assess the cumulative survival. Univariate and multivariate Cox proportional hazard regression models were used to identify the independent prognostic factors. Statistical analysis was performed using STATA software (version 9.2; StataCorp LP) and presented with GraphPad Prism 5 (GraphPad Software, Inc.).

\section{Results}

TGM3 is downregulated in CRC tissues and associated with clinicopathological features. In order to preliminarily gain an insight into the function of TGM3 in CRC, TGM3 expression was examined in $100 \mathrm{CRC}$ tissues and paired adjacent normal tissues. TGM3 was demonstrated to be significantly downregulated in CRC tissues compared with normal tissues at both the mRNA (Fig. 1A) and protein level (Fig. 1B and C). The patients were then divided into TGM3 high and TGM3 low groups according to the median value of TGM3 (Table I).

Further analyses revealed that TGM3 expression was significantly associated with invasion status $(\mathrm{P}=0.026)$, tumor stage $(\mathrm{P}=0.001)$ and liver metastasis $(\mathrm{P}=0.016$; Table $\mathrm{I})$. Furthermore, Kaplan-Meier curves combined with log-rank 


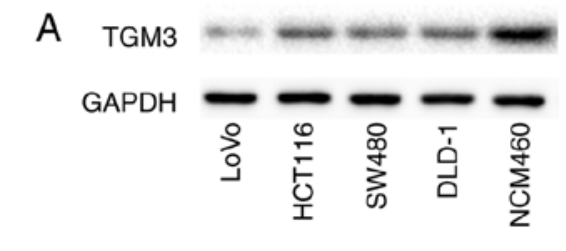

B
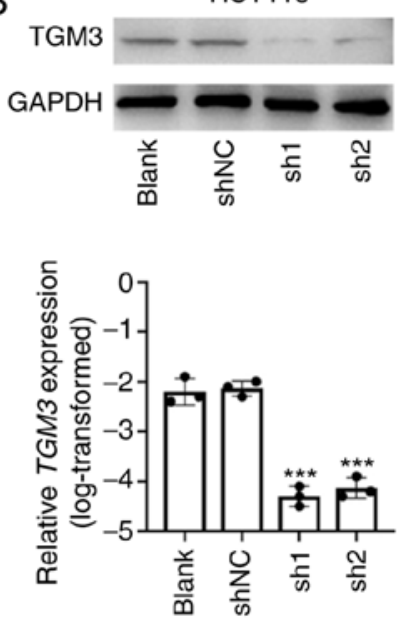
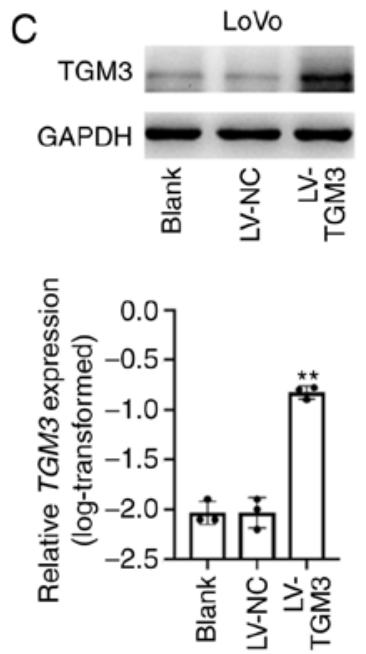
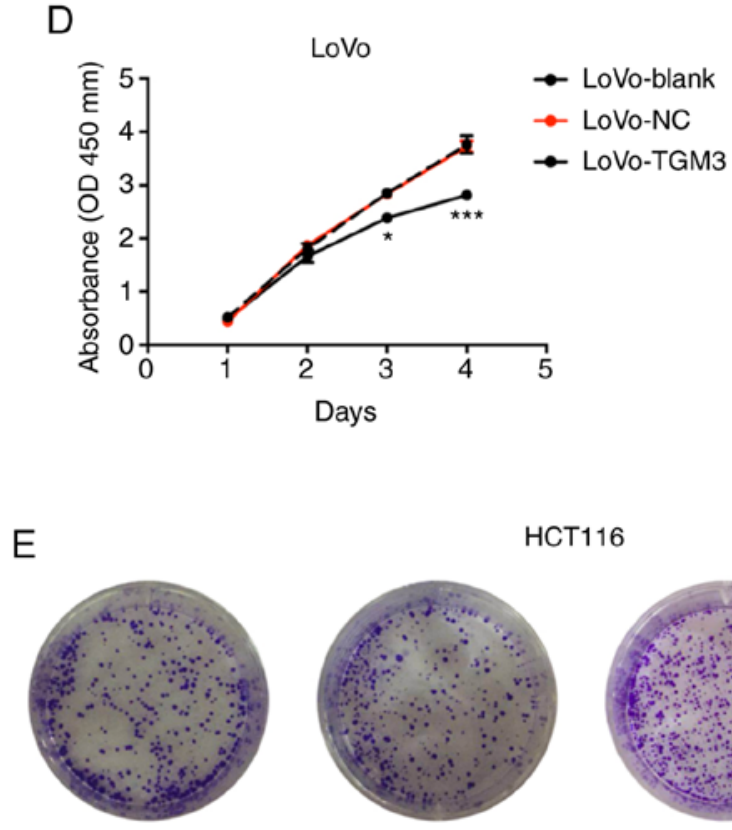

Blank

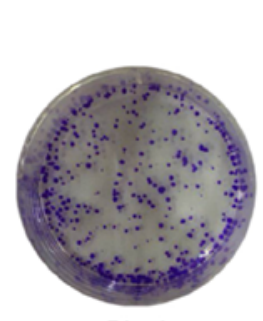

Blank

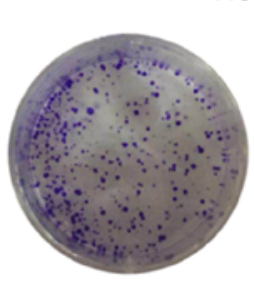

shNC

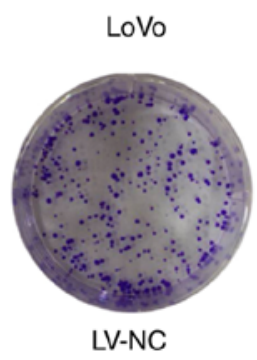

HCT116

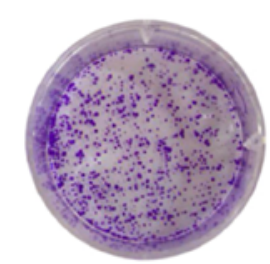

sh1

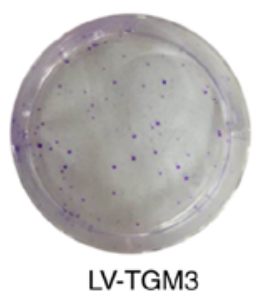

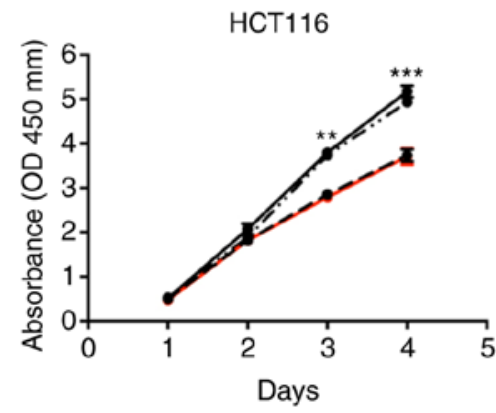

$\rightarrow$ HCT116-blank

$\rightarrow$ HCT116-NC

$\rightarrow$ HCT116-sh1

$\rightarrow$ HCT116-sh2

Figure 2. TGM3 is downregulated in CRC cell lines and suppresses cell viability in vitro. (A) The protein expression of TGM3 in CRC cell lines and normal colon epithelial NCM460 cells. (B) Knockdown efficiency of TGM3 by shRNA in HCT116 cells was confirmed via western blotting. (C) Overexpression efficiency of TGM3 by lentivirus (LV) in LoVo cells was confirmed via western blotting. (D) Cell Counting Kit-8 assay was performed to detect the proliferation ability in HCT116 cells (control and TGM3 knockdown) and LoVo cells (control and TGM3 overexpression). (E) Colony formation ability in HCT116 cells (control and TGM3 knockdown) and LoVo cells (control and TGM3 overexpression). All experiments were performed three times independently, and data are presented as the mean \pm standard error of the mean. ${ }^{*} \mathrm{P}<0.05$ and $^{* * *} \mathrm{P}<0.01$ and ${ }^{* * * *} \mathrm{P}<0.001$ vs. controls. NC, negative control sequence; sh, short hairpin; TGM3, transglutaminase; CRC, colorectal cancer.

tests confirmed that TGM3 expression was significantly associated with overall survival and cancer-specific survival in patients with CRC (Fig. 1D), which was also validated with the univariate and multivariate analyses (Tables II and III).
TGM3 is downregulated in CRC cells. Consistent with the results in the human CRC tissues, TGM3 expression was detected in different cell lines in the present study and it was revealed that the expression of TGM3 at the protein level 
A

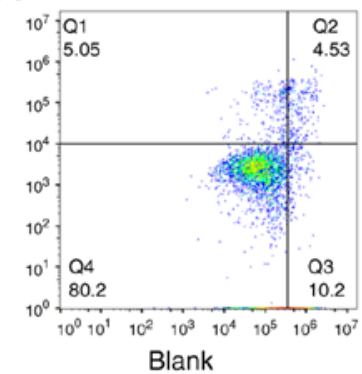

HCT116
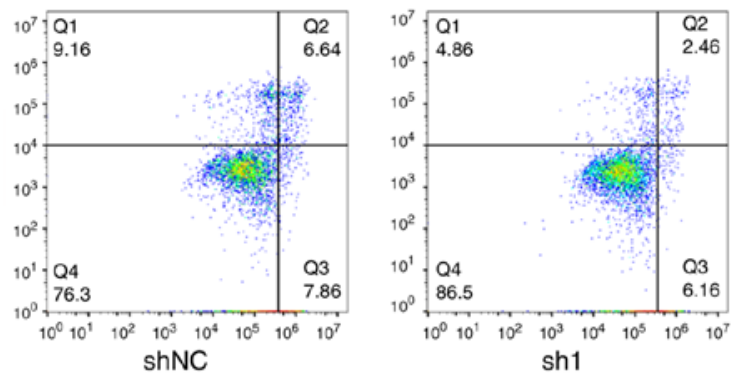

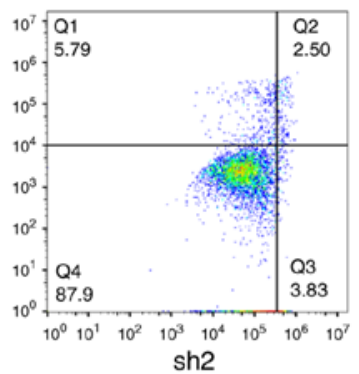

sh2

LoVo

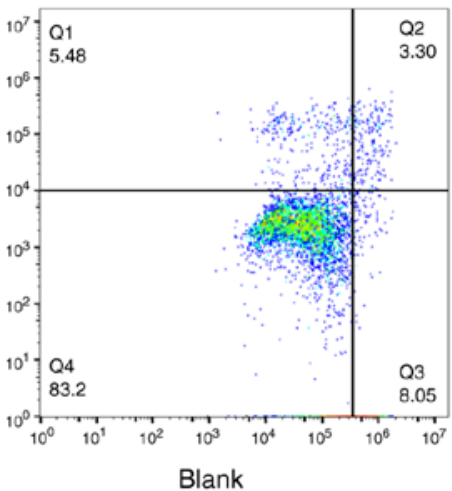

B

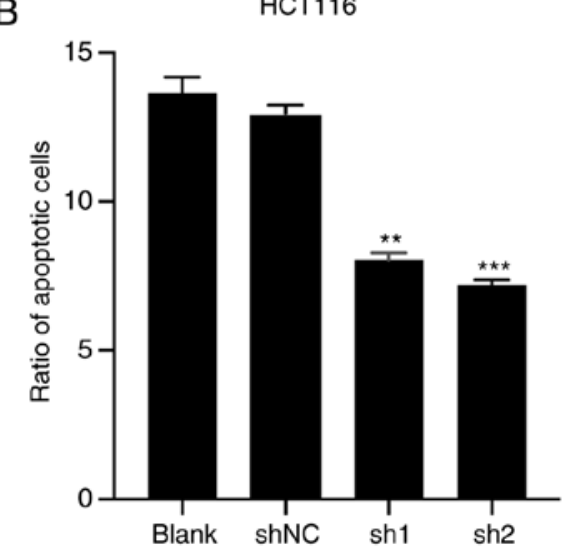

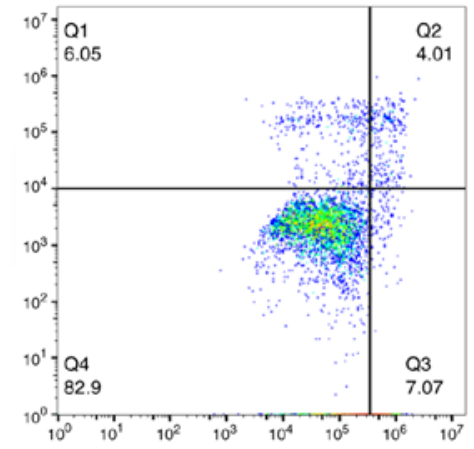

LV-NC

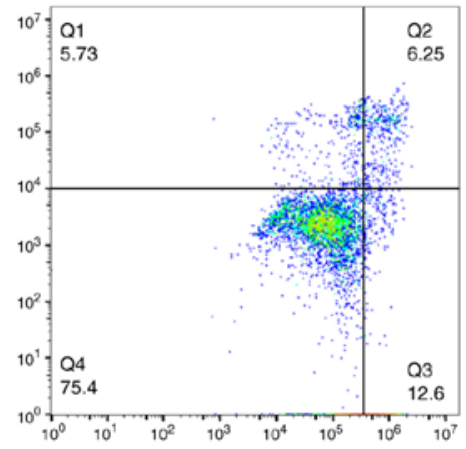

LV-TGM3

LoVo

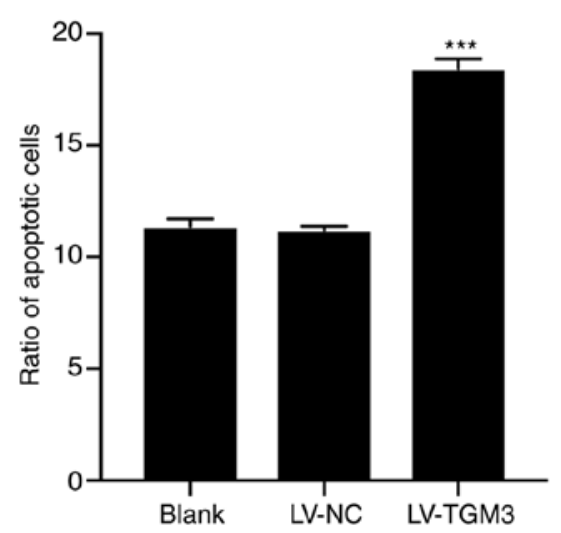

Figure 3. TGM3 promotes cell apoptosis in CRC cells. (A) The apoptosis rate of HCT116 and LoVo cells was detected by FACs. (B) The comparative analysis of apoptotic cells is presented. All experiments were performed three times independently and data are presented as the mean \pm standard error of the mean. ${ }^{* *} \mathrm{P}<0.01$ and $^{* * *} \mathrm{P}<0.001$. NC, negative control sequence; sh, short hairpin; LV, lentivirus; TGM3, transglutaminase 3; CRC, colorectal cancer.

was downregulated in the CRC cell lines compared with that in the NCM460 cells (Fig. 2A). When performing the gain- and loss-of-function assays, LoVo and HCT116 cells were selected to construct TGM3 overexpression and knockdown cells, respectively, in vitro by transfecting cells with a TGM3-overexpressing lentivirus or TGM3 specific shRNAs. The western blotting results further confirmed the knockdown and overexpression efficiency of TGM3 in the HCT116 and LoVo cells (Fig. 2B and C).

TGM3 suppresses CRC cell proliferation in vitro. In order to elucidate the role of TGM3 in the proliferation of CRC cells, CCK-8 and colony formation assays were performed. Knockdown of TGM3 significantly promoted cell viability in the HCT116 cells (Fig. 2D), whereas overexpression of TGM3 significantly inhibited cell proliferation in the LoVo cells
(Fig. 2D). Consistently, HCT116 cells transfected with shRNAs exhibited significantly increased colony formation ability, whereas LoVo cells transfected with TGM3-overexpressing lentivirus exhibited the opposite results (Fig. 2E).

TGM3 promotes cell apoptosis and suppresses the cell cycle of CRC cells in vitro. The FACs assay was utilized to investigate the cell apoptosis rate and cell cycle distribution in the HCT116 and LoVo cells. The results revealed that knockdown of TGM3 in HCT116 cells significantly decreased the percentage of apoptotic cells, whereas TGM3 overexpression in LoVo cells significantly enhanced the rate of apoptosis (Fig. 3A and B). Meanwhile, HCT116 cells transfected with the shRNA demonstrated a significantly higher percentage of cells in the $\mathrm{G}_{2}+\mathrm{S}$ phase and a significantly decreased percentage of cells in the $G_{1}$ phase, whereas LoVo cells transfected with the 
A
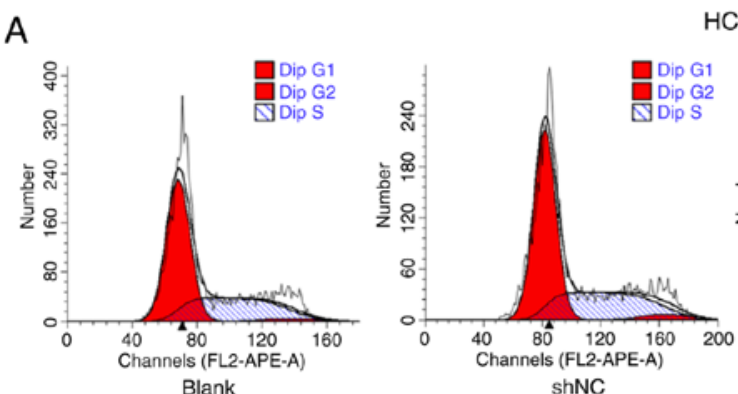

HCT116

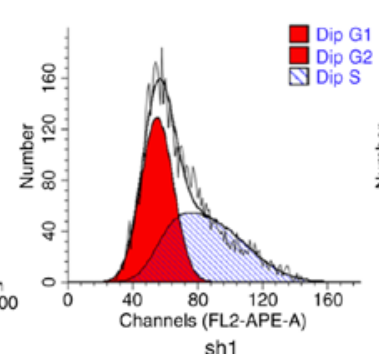

sh1

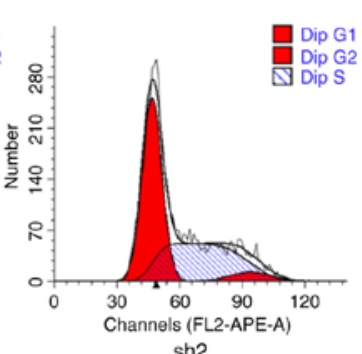

sh2

LoVo

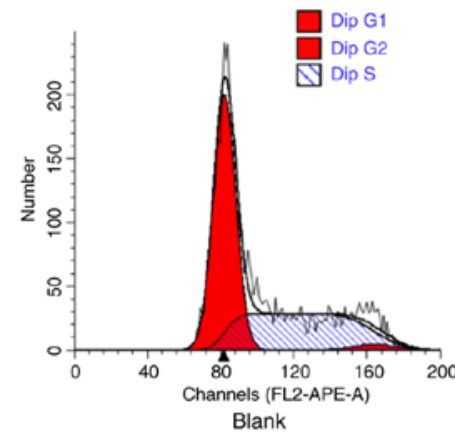

B

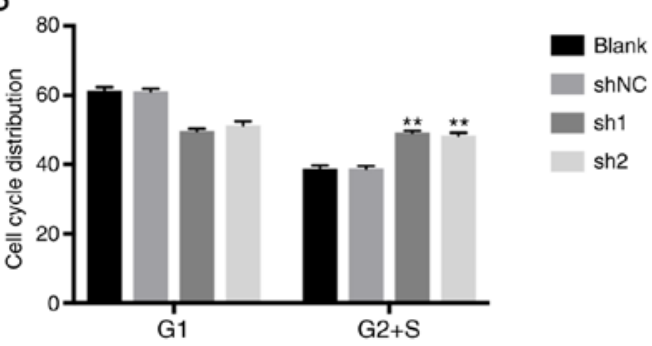

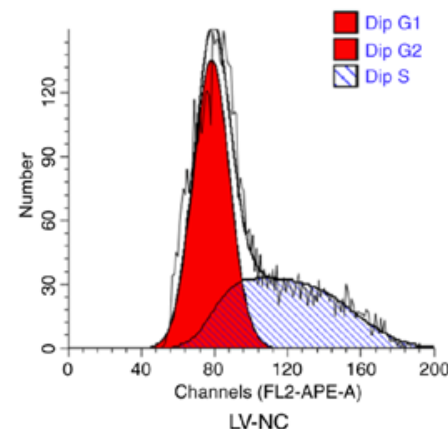

LV-NC

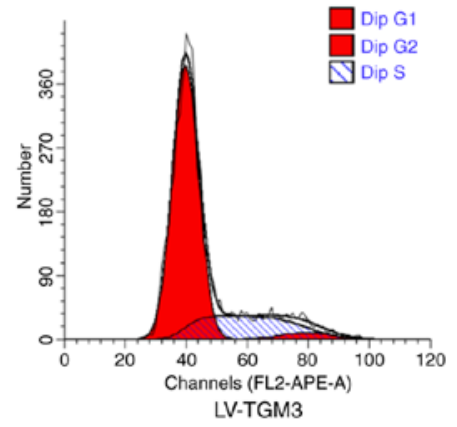

LoVo

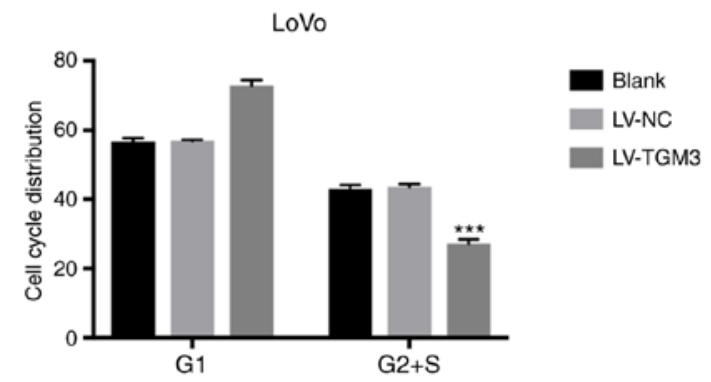

Figure 4. TGM3 arrests the cell cycle in CRC cells. (A) The cell cycle distribution of LoVo and HCT116 cells was detected using flow cytometry. (B) The comparative analysis of cell populations in the $\mathrm{G}_{0} / \mathrm{G}_{1}$ and $\mathrm{S}$ phases are presented. All experiments were performed three times independently and data are presented as the mean \pm standard error of the mean. ${ }^{* *} \mathrm{P}<0.01$ and ${ }^{* * *} \mathrm{P}<0.001$ vs. controls. NC, negative control sequence; sh, short hairpin; $\mathrm{LV}$, lentivirus; TGM3, transglutaminase 3; CRC, colorectal cancer.

TGM3-overexpressing lentivirus exhibited the reverse results (Fig. 4A and B).

TGM3 suppresses the migration and invasion of CRC cells in vitro. A Transwell assay was performed to assess the migration and invasion abilities of HCT116 and LoVo cells. The results revealed that the cells that translocated to the Transwell with or without Matrigel were significantly increased when TGM3 was silenced in HCT116 cells (Fig. 5A-C), whereas TGM3 overexpression in LoVo cells significantly decreased the number of cells that translocated to the Transwell with or without Matrigel (Fig. 5D-F). These results demonstrated that TGM3 suppresses the migration and invasion ability of CRC cells.

Upregulation of TGM3 inhibits tumor proliferation and metastasis in vivo. In order to investigate whether TGM3 plays a role in tumor growth in vivo, subcutaneous xenotransplantation models were constructed using nude mice. TGM3-knockdown HCT116 cells exhibited a significantly increased tumor size and tumor weight compared with the control group (Fig. 6A and B). Meanwhile, a tail vein metastasis model in nude mice using LoVo cells was performed in order to investigate whether
TGM3 affects tumor metastasis in vivo. A total of 5 weeks after the injection, hematoxylin and eosin staining revealed that the overexpression of TGM3 was associated with decreased lung metastases (Fig. 6C-E). All these results demonstrated that TGM3 suppressed proliferation and metastasis in vivo in CRC.

TGM3 represses the EMT process and activation of the PI3K/AKT signaling pathway in CRC cells. In order to determine whether EMT is mediating the inhibitory effect of TGM3 on proliferation and metastasis, the present study investigated the expression levels of numerous different EMT markers. As expected, overexpression of TGM3 increased the expression level of E-cadherin and decreased the levels of N-cadherin and vimentin, while knockdown of TGM3 decreased the expression level of E-cadherin and increased the levels of N-cadherin and vimentin (Fig. 7A and B). All these results revealed that TGM3 could suppress the EMT process in CRC cells. Notably, the protein levels of p-PI3K and p-AKT were decreased when TGM3 was overexpressed in LoVo cells, whereas they were increased when TGM3 was knocked down in HCT116 cells. However, no significant differences were observed in total PI3K and AKT expression, suggesting that 
A
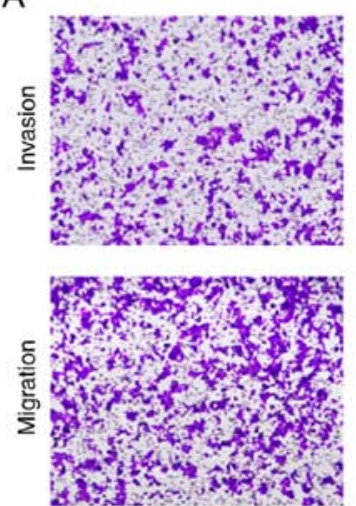

Blank
HCT116
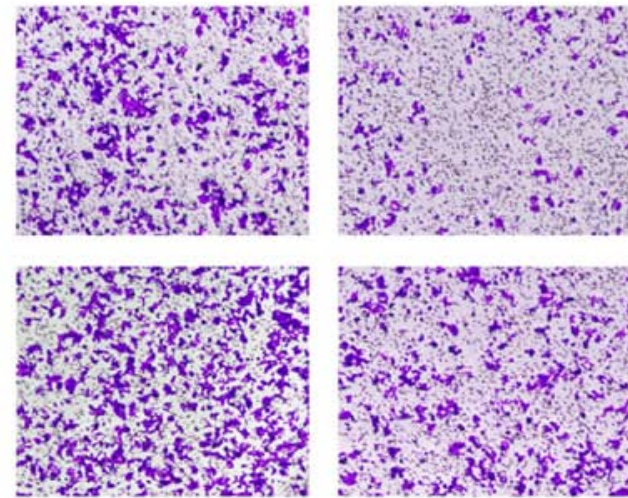

shNC

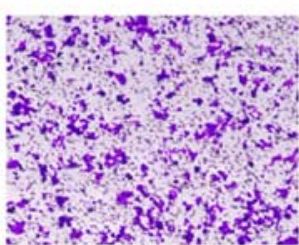

$\operatorname{sh} 1$
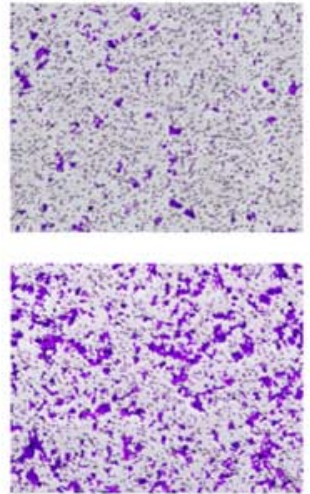

sh2
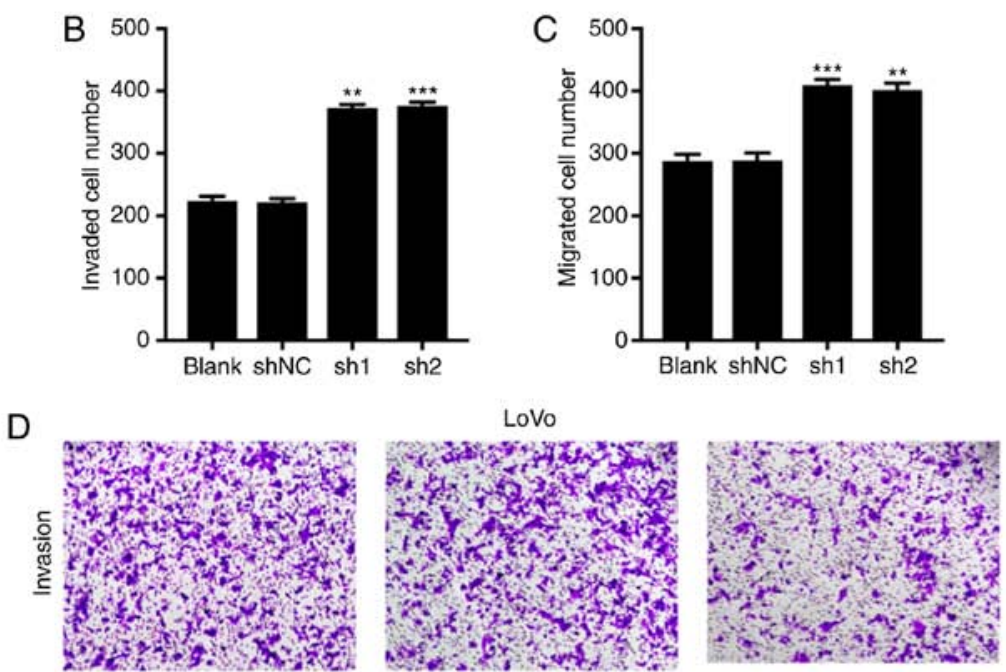

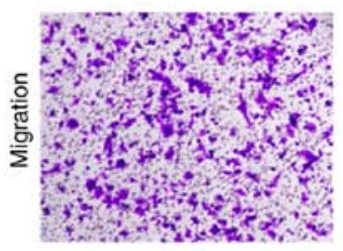

Blank

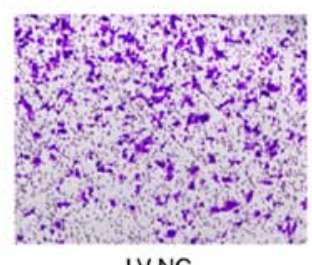

LV-NC

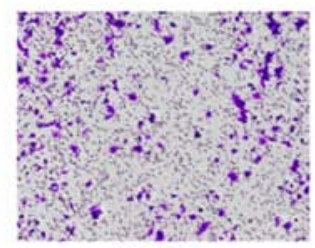

LV-TGM3
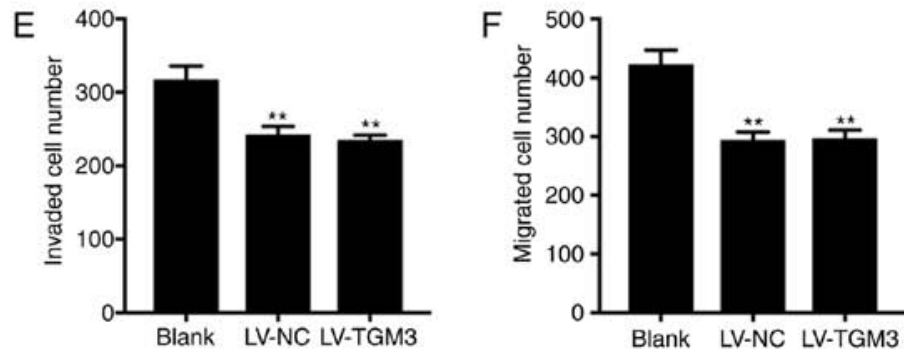

Figure 5. TGM3 suppresses the migration and invasion ability of CRC cells. (A) Representative images of HCT116 cells translocated with or without Matrigel. (B) The quantity of invasive HCT116 cells through the Matrigel. (C) The quantity of migrated HCT116 cells through the membrane is presented. (D) Representative images of LoVo translocated with or without Matrigel. Statistical analysis of (E) invasive and (F) migrated cells. All experiments were performed three times independently and data are presented as the mean \pm standard error of the mean. ${ }^{* * *} \mathrm{P}<0.01$ and ${ }^{* * * *} \mathrm{P}<0.001$. NC, negative control sequence; sh, short hairpin; LV, lentivirus; TGM3, transglutaminase 3; CRC, colorectal cancer.

TGM3 inhibits activation of the PI3K/AKT signaling pathway (Fig. 7A and B).

In order to further assess whether TGM3 inhibits the EMT process through the PI3K/AKT signaling pathway, an AKT inhibitor named MK-2206 $2 \mathrm{HCl}$ was utilized. Treatment with MK-2206 $2 \mathrm{HCl}$ reversed the expression level of mesenchymal markers and activation of the PI3K/AKT signaling pathway mediated by TGM3 knockdown (Fig. 7C). Furthermore, inactivation of PI3K/AKT by MK-2206 $2 \mathrm{HCl}$ also reversed cell phenotypes, such as colony formation ability (Fig. 8A), cell viability (Fig. 8B), apoptosis (Fig. 8C), cell cycle distribution (Fig. 8D), invasion and migration ability (Fig. 8E). 
A

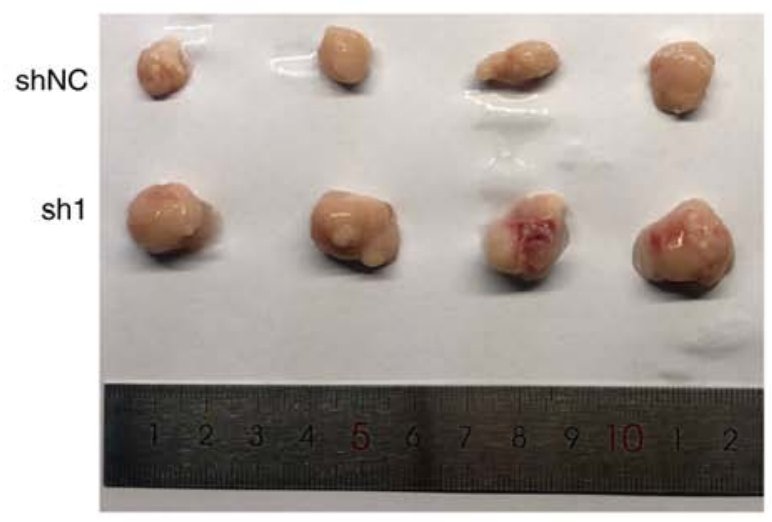

LV-TGM3

C

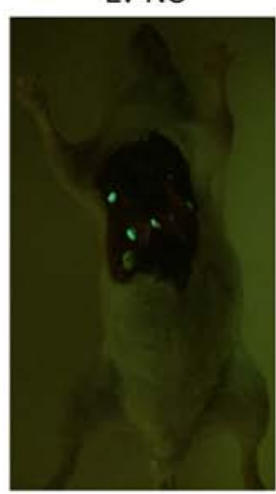

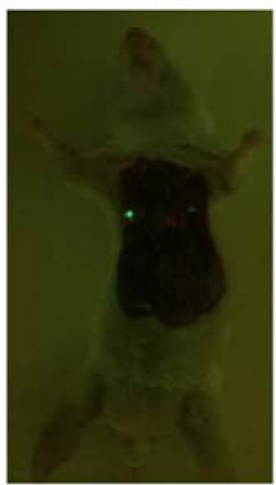

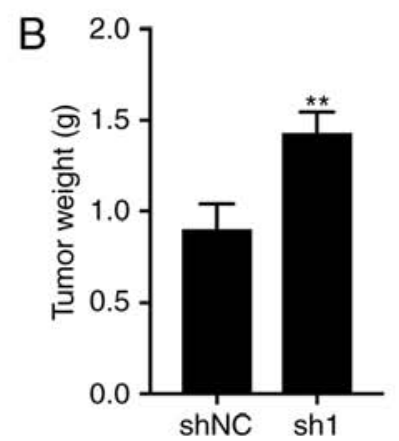

Figure 6. Upregulation of TGM3 inhibits tumor proliferation and metastasis in vivo. (A) Representative images of the isolated tumor tissues from the shTGM3 group and shNC group are showed. (B) Statistical analysis of isolated tumor weight. TGM3-knockdown HCT116 cells exhibited a significantly increased tumor size and tumor weight compared with the control group. (C) In the tail vein xenograft model, mice $(\mathrm{n}=10)$ were injected with LoVo cells $\left(2 \times 10^{6}\right.$ suspended in $200 \mu$ PBS) through the tail vein and sacrificed 5 weeks later; lung metastasis was investigated in each group respectively by an in vivo fluorescence imaging system. (D) All the results of lung metastases were validated by histological examination (H\&E). Original magnification, x200. (E) Statistical analysis of lung metastases in the two groups. Data are presented as the mean \pm standard deviation. ${ }^{* *} \mathrm{P}<0.01$. NC, negative control sequence; sh, short hairpin; LV, lentivirus; TGM3, transglutaminase 3 .

A

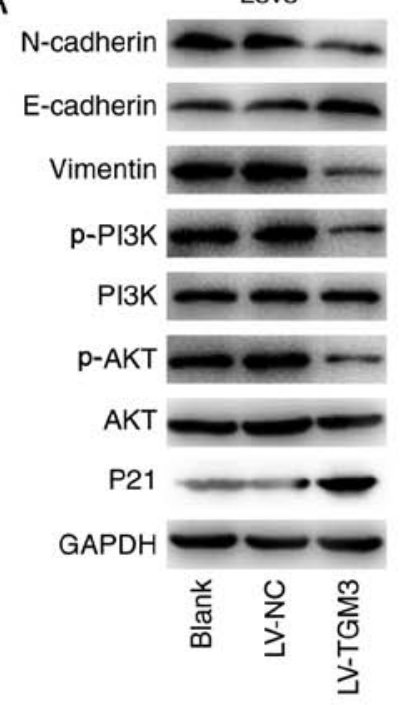

B

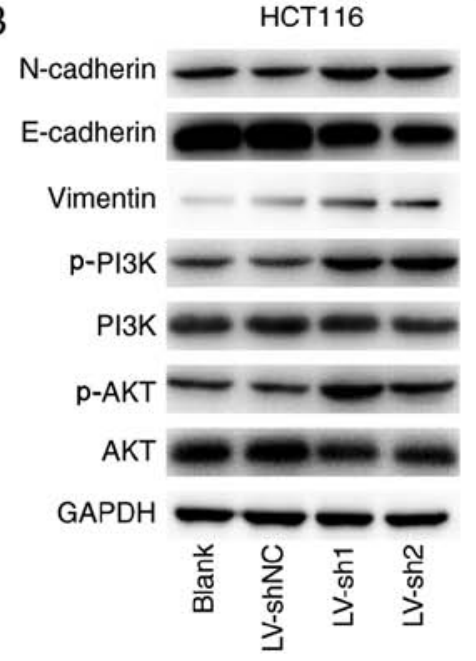

C

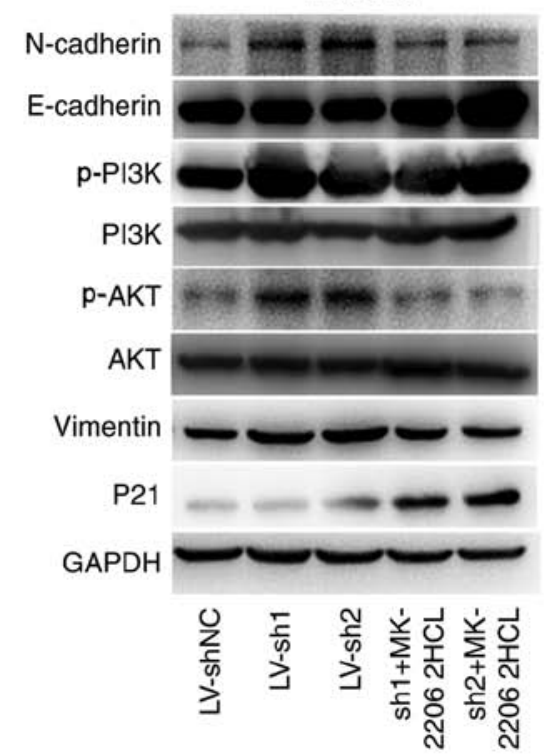

Figure 7. TGM3 represses the EMT process and activation of the PI3K/AKT signaling pathway in CRC cells. Expression levels of EMT markers (E-cadherin, $\mathrm{N}$-cadherin and vimentin), PI3K/AKT effectors (p-PI3K, PI3K, p-AKT, AKT) and a proliferation marker (P21) were detected via western blotting in (A) HCT116 cells following TGM3 knockdown and (B) LoVo cells following TGM3 overexpression. (C) Expression levels of EMT markers (E-cadherin, $\mathrm{N}$-cadherin and vimentin), PI3K/AKT effectors (p-PI3K, PI3K, p-AKT and AKT) and a proliferation marker (P21) in HCT116 cells in the different groups (shNC, sh1, sh2, sh1+MK-2206 2HCl). CRC, colorectal cancer; NC, negative control sequence; sh, short hairpin; LV, lentivirus; TGM3, transglutaminase 3; MK-2206 2HCl, AKT inhibitor. 
A

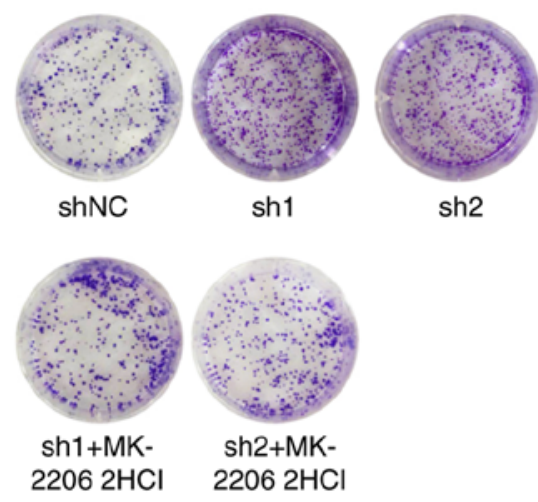

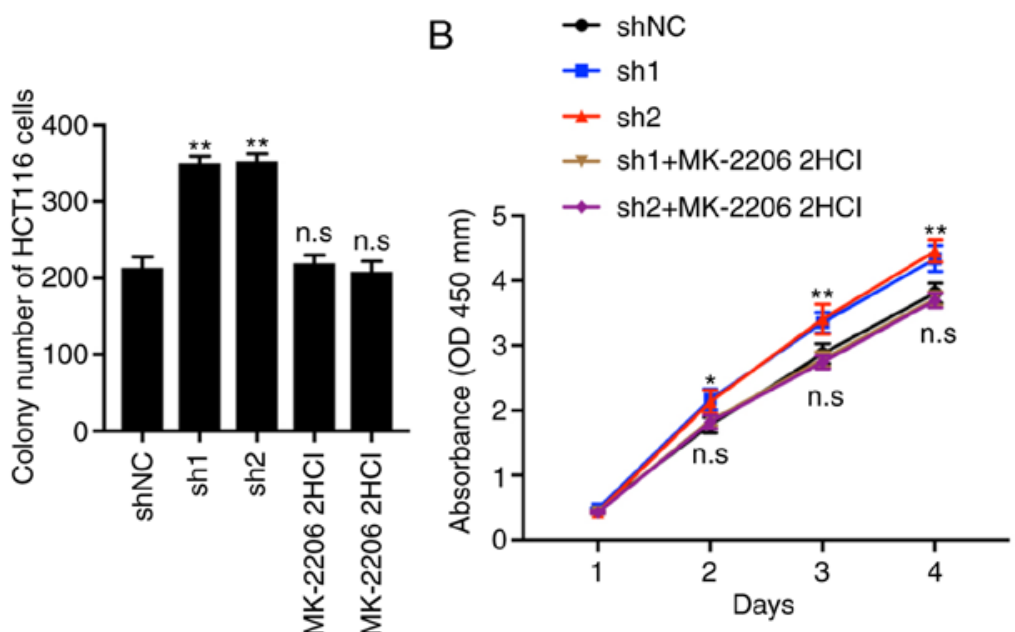

C
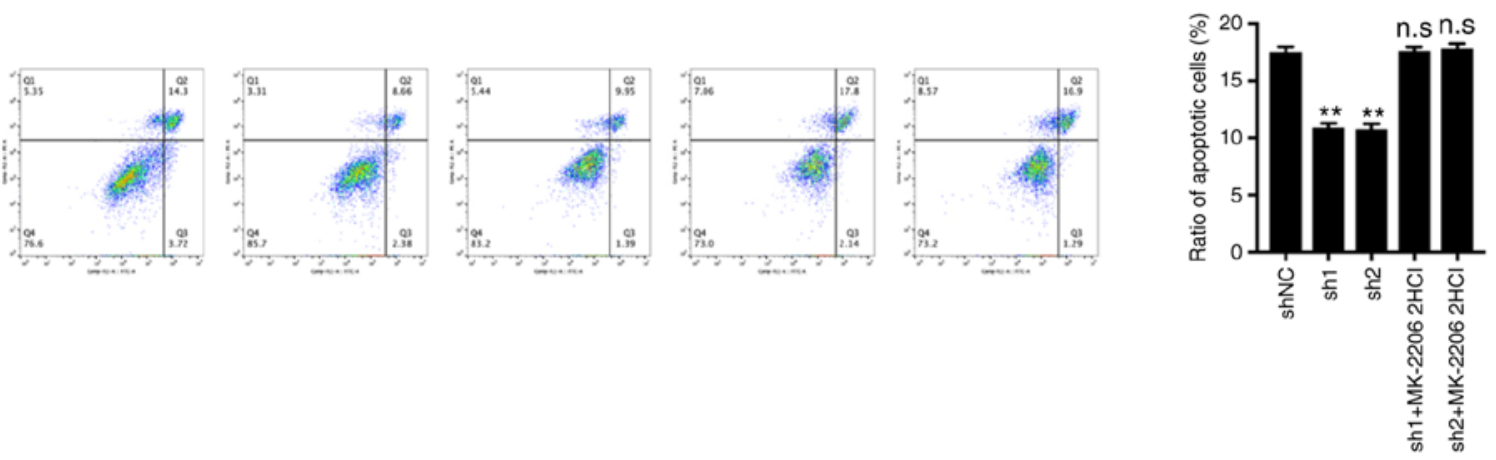

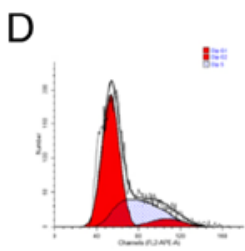

$\operatorname{shNC}$

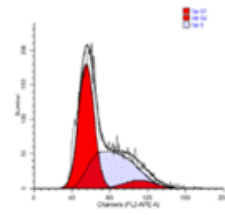

$\operatorname{sh} 1$

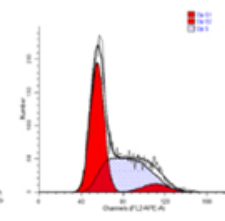

$\operatorname{sh} 2$

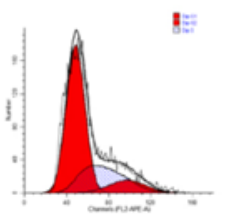

sh1+MK$22062 \mathrm{HCl}$
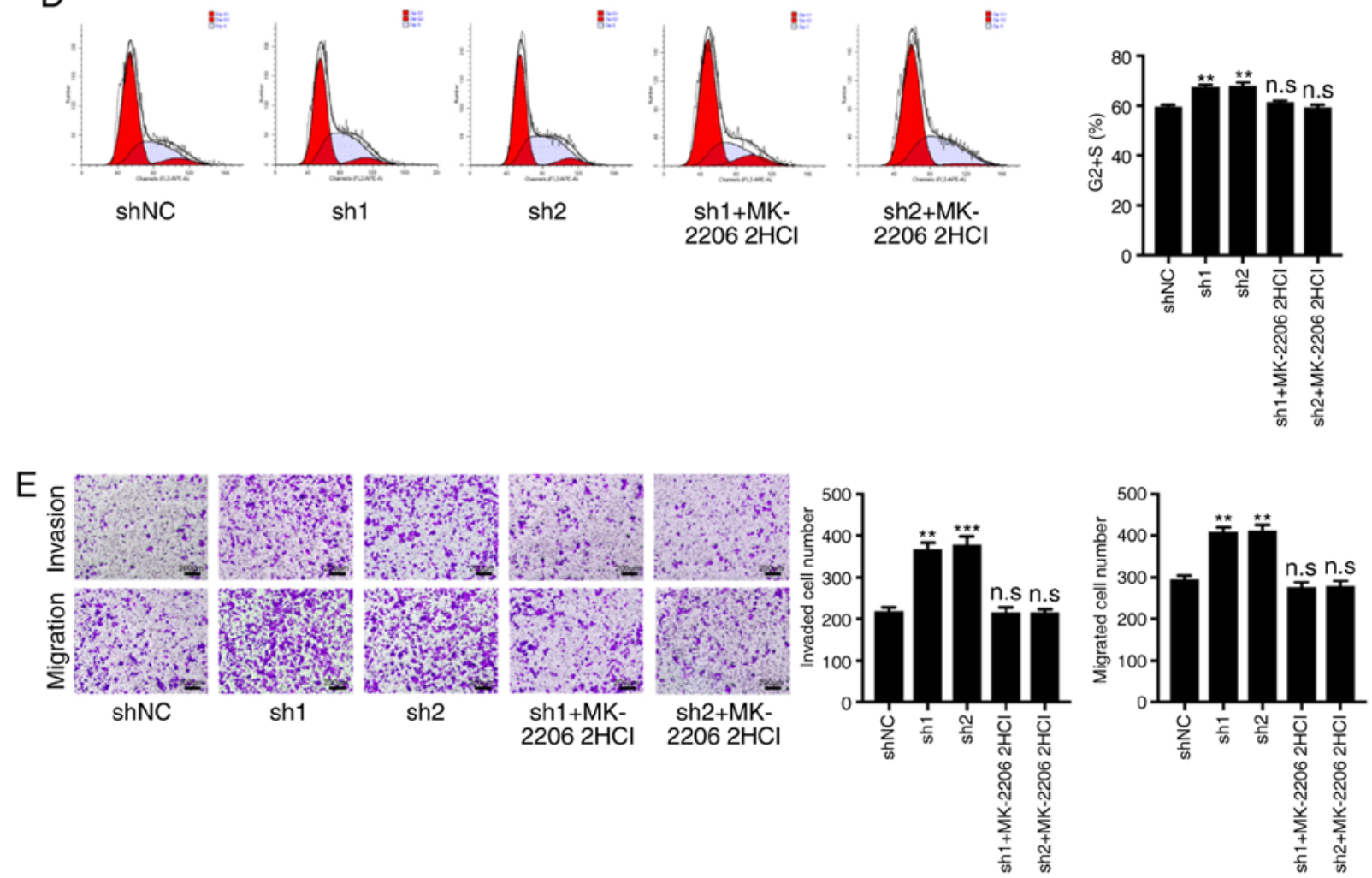

Figure 8. Treatment with an AKT inhibitor, MK-2206 2HCl, reverses the phenotype caused by TGM3 knockdown. (A) Colony-forming abilities of HCT116 cells in the different groups (shNC, sh1, sh2 and sh1+MK-2206 2HCl). (B) The Cell Counting Kit-8 assay was utilized to detect viability of HCT116 cells in the different groups (shNC, sh1, sh2 and sh1+MK-2206 2HCl). (C) cell apoptosis ratio and (D) the cell cycle distribution of HCT116 cells in the different groups (shNC, sh1, sh2 and sh1+MK-2206 2HCl) were measured using FACs. (E) The quantity of invasive and migrated HCT116 cells through the membrane in the different groups (shNC, sh1, sh2 and sh1+MK-2206 $2 \mathrm{HCl}$ ) is presented. ${ }^{*} \mathrm{P}<0.05$ and ${ }^{* *} \mathrm{P}<0.01$ and ${ }^{* * * *} \mathrm{P}<0.001$; n.s, not significant. NC, negative control sequence; sh, short hairpin; TGM3, transglutaminase 3; MK-2206 2HCl, AKT inhibitor. 


\section{Discussion}

Transglutaminases (TGMs) are a family of calcium-dependent enzymes that catalyze the formation of isopeptide bonds $(3,11)$. Transglutaminase 3 (TGM3), an epidermal transglutaminase expressed predominantly in the suprabasal layers of the stratified squamous epithelium, has been reported as a regulatory protein in a number of different types of cancer, and to serve as a prognostic biomarker (4-7). However, the role of TGM3 in colorectal cancer (CRC) and the underlying molecular mechanism remain unknown.

Epithelial-to-mesenchymal transition (EMT), a widely studied process involving the alteration of epithelial cells to mesenchymal cells (12), is considered to be critical in the proliferation and metastasis of various types of cancer. This process involves the acquisition of the expression of mesenchymal molecules, such as vimentin and $\mathrm{N}$-cadherin, together with the loss of epithelial cell adhesion molecules, such as E-cadherin $(11,12)$. The present study verified that TGM3 regulated the biological functions of CRC cells via modulating the EMT process by assessing the expression of classical EMT markers via western blotting. A number of signaling pathways have been reported to be involved in the regulation of the EMT process, among which PI3K/AKT is the most notable $(13,14)$. The present study then aimed to assess whether PI3K/AKT is necessary for TGM3-induced inhibition of the EMT process. As expected, phosphorylation of both PI3K and AKT were decreased following overexpression of TGM3, and increased following knockdown of TGM3. Nevertheless, more in-depth studies are required in order to elucidate the association between TGM3, EMT and the PI3K/AKT signaling pathway.

In summary, the present study focused on the novel molecule TGM3, which was significantly downregulated and positively correlated with the outcome in patients with CRC. Furthermore, evidence provided by in vitro and in vivo assays confirmed that TGM3 could repress the proliferation and metastasis of CRC by regulating the EMT process by inhibiting the PI3K/AKT signaling pathway.

\section{Acknowledgements}

Not applicable.

\section{Funding}

Not applicable.

\section{Availability of data and materials}

The analyzed data sets generated during the study are available from the corresponding author on reasonable request.

\section{Authors' contributions}

YF and DJ conducted the research. YF, YH, BJ and YZ performed the in vitro experiments. $\mathrm{YH}, \mathrm{JL}, \mathrm{WP}$ and $\mathrm{CZ}$ performed the in vivo experiments. YF, DJ, YH and DZ performed the data collection and analyses. YS and ZX designed the experiments and supervised the procedures and wrote the manuscript. All authors read and approved the manuscript and agree to be accountable for all aspects of the research in ensuring that the accuracy or integrity of any part of the work are appropriately investigated and resolved.

\section{Ethics approval and consent to participate}

All tissues were supplied by the tissue bank of the First Affiliated Hospital of Nanjing Medical University (ethical approval no. 2010-SR-091.A1). All animal experiments were approved by the Animal Ethics Committee of Nanjing Medical University.

\section{Patient consent for publication}

Not applicable.

\section{Competing interests}

The authors declare that they have no competing interests.

\section{References}

1. Torre LA, Bray F, Siegel RL, Ferlay J, Lortet-Tieulent J and Jemal A: Global cancer statistics, 2012. CA Cancer J Clin 65: 87-108, 2015.

2. Siegel R, DeSantis C, Virgo K, Stein K, Mariotto A, Smith T, Cooper D, Gansler T, Lerro C, Fedewa S, et al: Cancer treatment and survivorship statistics, 2012. CA Cancer J Clin 62: 220-241, 2012.

3. Griffin M, Casadio R and Bergamini CM: Transglutaminases: Nature's biological glues. Biochem J 368: 377-396, 2002.

4. Candi E, Schmidt R and Melino G: The cornified envelope: A model of cell death in the skin. Nat Rev Mol Cell Biol 6: 328-340, 2005.

5. Uemura N, Nakanishi Y, Kato H, Saito S, Nagino M, Hirohashi S and Kondo T: Transglutaminase 3 as a prognostic biomarker in esophageal cancer revealed by proteomics. Int J Cancer 124: 2106-2115, 2009

6. Wu X, Cao W, Wang X, Zhang J, Lv Z, Qin X, Wu Y and Chen W: TGM3, a candidate tumor suppressor gene, contributes to human head and neck cancer. Mol Cancer 12: 151, 2013.

7. Li W, Zhang Z, Zhao $\mathrm{W}$ and Han $\mathrm{N}$ : Transglutaminase 3 protein modulates human esophageal cancer cell growth by targeting the NF-KB signaling pathway. Oncol Rep 36: 1723-1730, 2016.

8. Nieto MA, Huang RY, Jackson RA and Thiery JP: EMT: 2016. Cell 166: 21-45, 2016.

9. De Craene B and Berx G: Regulatory networks defining EMT during cancer initiation and progression. Nat Rev Cancer 13: 97-110, 2013.

10. Larue L and Bellacosa A: Epithelial-mesenchymal transition in development and cancer: Role of phosphatidylinositol 3' kinase/AKT pathways. Oncogene 24: 7443-7454, 2005.

11. Lorand L and Graham RM: Transglutaminases: Crosslinking enzymes with pleiotropic functions. Nat Rev Mol Cell Biol 4: 140-156, 2003.

12. Radisky DC and LaBarge MA: Epithelial-mesenchymal transition and the stem cell phenotype. Cell Stem Cell 2: 511-512, 2008.

13. Thiery JP, Acloque $\mathrm{H}$, Huang RY and Nieto MA: Epithelial-mesenchymal transitions in development and disease. Cell 139: 871-890, 2009.

14. Yang J and Weinberg RA: Epithelial-mesenchymal transition: At the crossroads of development and tumor metastasis. Dev Cell 14: 818-829, 2008.

This work is licensed under a Creative Commons Attribution-NonCommercial-NoDerivatives 4.0 International (CC BY-NC-ND 4.0) License. 